\title{
Listeriose em ovinos associada ao consumo de silagem no Rio Grande do Norte*
}

\section{Listeriosis in sheep linked to silage consumption in Rio Grande do Norte}

\author{
Antônio Carlos Lopes Câmara, ${ }^{* *}$ Robério Gomes Olinda, ${ }^{* * *}$ Jael Soares Batista, ${ }^{* * * *}$ Francisco Marlon C. Feijó, ${ }^{* * * *}$ \\ Rafael Duarte Almeida*****
}

\begin{abstract}
Resumo
O relato objetivou descrever os achados epidemiológicos, clínico-patológicos, laboratoriais e microbiológicos em um surto de meningoencefalite em ovinos por Listeria monocytogenes associado ao consumo de silagem. A enfermidade acometeu oito ovinos pertencentes a um rebanho de 600 animais, alcançando letalidade de $100 \%$. A única ovelha examinada apresentou apatia, febre, cegueira bilateral com midríase, hipotonia lingual, nistagmo e torneio à direita com quedas esporádicas. A hematologia revelou linfopenia absoluta com inversão na relação de linfócito / neutrófilo $(0,16)$. A análise do líquido cefalorraquidiano (LCR) mostrou aspecto turvo e pleocitose neutrofílica (92 leucócitos/ $\mu \mathrm{L}$ ). L. monocytogenes foi isolada em quatro alíquotas de LCR submetidas à cultura microbiológica. Em quatro ovinos necropsiados, as lesões macroscópicas consistiram de congestão das meninges e turbidez do LCR. Microscopicamente, a principal característica foi meningoencefalite do troco encefálico, bulbo, ponte, mesencéfalo e medula oblonga, com microabscessos multifocais e gliose. Infiltrado neutrofílico e linfocítico multifocal nos fascículos do nervo trigêmeo foi também observado. Os autores reiteram a importância das medidas preventivas, a fim de reduzir a incidência da listeriose.
\end{abstract}

Palavras-chave: doença em ovinos, Listeria monocytogenes, meningoencefalite, neuropatologia.

\begin{abstract}
This report aimed to describe epidemiological, clinical-pathological, laboratorial and microbiological findings in an outbreak of meningoencephalitis in sheep due to $L$. monocytogenes linked to silage consumption. The disease affected eight sheep from a 600 sheep flock, achieving $100 \%$ lethality. The only ewe examined presented apathy, fever, bilateral blindness with mydriasis, tongue hypotony, nystagmus and right circling with sporadic falls. Hematology revealed absolute lymphopenia with inversion in the lymphocyte/neutrophil ratio (0.16). Cerebrospinal fluid (CSF) analysis showed turbid aspect and neutrophilic pleocytosis (92 leukocytes $/ \mu \mathrm{L}$ ). L. monocytogenes was isolated from four CSF samples submitted to microbiological assays. In four necropsied sheep, gross lesions included meningeal congestion and CSF clouding. Microscopically, the main feature was meningoencephalitis of the brainstem, bulb, pons, mesencephalus and medulla oblongata, with multifocal microabscesses and gliosis. Multifocal lymphocytic and neutrophilic infiltrate in the trigeminal nerve fascicles was also observed. The authors reiterate the importance of adequate preventive measures to reduce incidence of listeriosis.
\end{abstract}

Keywords: Listeria monocytogenes, meningoencephalitis, neuropathology, sheep disease.

\section{Introdução}

A listeriose é causada pela Listeria monocytogenes (bactéria Gram-positiva e anaeróbica facultativa), considerada importante enfermidade infecciosa que afeta grande variedade de mamíferos, incluindo ruminantes, animais monogástricos e humanos (Schild, 2007; Brugére-Picoux, 2008; Rocha et al., 2013). Em ruminantes, as principais apresentações clínicas incluem ceratoconjuntivite/uveíte, septicemia, abortos, mastite, mielite, gastroenterite e distúrbios neurológicos, os mais comuns, caracterizados por meningoencefalite com formação de microabscessos no tronco encefálico (Brugére-Picoux, 2008).

No Brasil, a forma neurológica de listeriose em pequenos ruminantes é descrita em caprinos no Rio Grande do Sul (Rissi et al., 2006) e Paraíba (Guedes et al., 2007). Em ovinos, existem relatos da enfermidade nos estados da Paraíba (Guedes et al., 2007), Rio Grande do Sul (Ribeiro et al., 2006; Rissi et al., 2010) e Paraná (Rissi et al., 2010). Em estudo retrospectivo no Nordeste brasileiro, principalmente na Paraíba, os casos de listeriose representaram $6,34 \%$ das enfermidades do sistema nervoso central (SNC) diagnosticadas em ovinos e caprinos (Guedes et al., 2007). Tal fato demonstra a importância desta doença em criatórios no semiárido brasileiro.

Em países da América do Norte e Europa, a listeriose é associada com a ingestão de silagem pobremente fermentada $(\mathrm{pH}>5,5)$, que se apresenta como excelente substrato para a sobrevivência e multiplicação do micro-organismo (Morin, 2004; Brugére-Picoux, 2008). No Brasil, apenas um surto acometendo dois ovinos na região serrana do Rio Grande do Sul foi associado ao consumo de silagem de baixa qualidade em conjunto com as lesões orais decorrentes das mudas dentárias (Ribeiro et al., 2006).

*Recebido em 12 de dezembro de 2013 e aceito em 2 de abril de 2014.

**Hospital Veterinário, Universidade Federal Rural do Semi-Árido (UFERSA). Autor para correspondência: aclcamara@yahoo.com.br.

***Hospital Veterinário, Centro de Saúde e Tecnologia Rural, Universidade Federal de Campina Grande.

****Docente do Curso de Medicina Veterinária, Departamento de Ciências Animais, UFERSA

***** Médico veterinário autônomo. 
Em estudo da década de 1990, os autores foram capazes de determinar o impacto econômico da doença em um rebanho de 936 ovinos expostos a silagem contaminada por L. monocytogenes, confirmando sua importância econômica oriunda da alta letalidade de animais e custos de tratamento. O custo total decorrente da morte de ovelhas e cordeiros foi estimado em 3.146 dólares (Nash et al., 1995). Assim, devido à escassez de dados nacionais sobre surtos de listeriose associados à ingestão de silagem, e inexistência de relatos da enfermidade no Rio Grande do Norte, os objetivos deste relato foram descrever os achados epidemiológicos, clínicopatológicos, laboratoriais e microbiológicos de um surto de meningoencefalite por $L$. monocytogenes em ovinos.

\section{Relato do surto}

Os dados foram obtidos junto ao proprietário e médico veterinário responsável pela assistência técnica, durante o surto de listeriose (fevereiro de 2011) em uma fazenda localizada no município de Governador Dix-Sept Rosado, região semiárida do Rio Grande do Norte. Foram resgatadas as informações relacionadas com os dados epidemiológicos, achados clínicopatológicos, laboratoriais e microbiológicos.

O rebanho era composto por aproximadamente 600 ovinos. $\mathrm{Na}$ propriedade, ocorreu o óbito de quatro ovinos com sintomatologia nervosa e evolução clínica de até quatro dias. Outros quatro ovinos mestiços, com idade variando de cinco meses a cinco anos, foram trazidos ao Hospital Veterinário da Universidade Federal do Semiárido, dos quais apenas um chegou com vida, sendo submetido ao exame clínico segundo as recomendações de Diffay et al. (2004) e exame neurológico de acordo com Mayhew (2009). Amostras sanguíneas foram colhidas através de venipunção jugular em tubo a vácuo com e sem anticoagulante EDTA $10 \%$ para realização do hemograma e dosagens bioquímicas (uréia, creatinina, gamaglutamil transferase (GGT), aspartato aminotransferase (AST) e proteínas totais). Coletou-se amostra de líquido cefalorraquidiano (LCR) na cisterna magna para análise de acordo com a metodologia de Scott (2010). Alíquotas do LCR, oriundas dos três ovinos mortos e do examinado clinicamente, foram semeadas em Ágar sangue de carneiro desfibrinado (5\%) para a realização da cultura microbiológica, seguindo-se à incubação em estufa bacteriológica a temperatura de $37^{\circ} \mathrm{C}$ por $48 \mathrm{~h}$ em microaerofilia. Após isso, realizou-se a análise das características macroscópicas, morfotintoriais (pelo método de coloração de Gram) e perfil bioquímico (MacFaddin, 2000).

Os quatro ovinos foram encaminhados para diagnóstico anatomopatológico, pois a ovelha examinada veio a óbito 24 horas após início do tratamento. O tratamento consistiu de antibioticoterapia com associação de penicilinas e estreptomicina (Pentabiótico®, Fort Dodge Saúde Animal Ltda, São Paulo, Brasil: 44.000 Ul. $\mathrm{kg}^{-1}$, via intramuscular); anti-inflamatório não esteroidal (Flumegan® Injetável, Marcolab Ltda, Rio de Janeiro, Brasil: 2,2 mg. $\mathrm{kg}^{-1}$, via intramuscular) e correção do desequilíbrio hídrico-eletrolítico. Fragmentos dos órgãos da cavidade abdominal, torácica e o SNC foram coletados e fixados em formol a $10 \%$. Após fixação, as lâminas histológicas foram confeccionadas em cortes de $5 \mathrm{~mm}$ e coradas com Hematoxilina e Eosina (HE).

\section{Resultados e discussão}

No Brasil, os surtos da forma caracterizada por meningoencefalite decorrem da penetração bacteriana em lesões oriundas de traumatismos na mucosa oral causados por alimentos grosseiros ou infecções das cavidades dentárias, invadindo o nervo trigêmeo e alcançando o tronco encefálico (Schild, 2007). Em países da América do Norte e Europa, a epidemiologia da doença é associada à ingestão de silagem de baixa qualidade (Morin, 2004; Brugére-Picoux, 2008). O crescimento de $L$. monocytogenes é inibido em silagens com $\mathrm{pH} \leq 5,5$, sendo necessário alcançar condições anaeróbias para obtenção do pH baixo. A incapacidade de promover tais condições (por exemplo: devido à má consolidação, vedação atrasada do silo, demora no armazenamento da silagem ou quebra do invólucro de vedação) permite a proliferação de L. monocytogenes e muitas outras bactérias, leveduras e bolores (Dunière et al., 2013).

No surto descrito, em particular, o proprietário relatou que o rebanho de ovinos era suplementado no período de estiagem com silagem de milho e sorgo forrageiro, armazenada em silos tipo trincheira; com presença de áreas mofadas nas bordas. Os primeiros casos ocorreram aproximadamente um mês após o término da utilização da silagem na alimentação destes ovinos, corroborando dados anteriores que citam o período de incubação da forma encefálica variando entre quatro e seis semanas (Ribeiro et al., 2006; Brugére-Picoux, 2008). Silagem armazenada em silos trincheira é particularmente propensa à fermentação inadequada e proliferação de L. monocytogenes, mas os problemas podem ocorrer em qualquer sistema de armazenamento de silagem (Dunière et al., 2013). Portanto, em surtos da forma neurológica da listeriose, a qualidade e as condições de armazenamento da silagem devem ser cuidadosamente examinadas (Ribeiro et al., 2006). Por vezes isto não é possível, como neste relato, em que toda a silagem afetada tinha sido consumida ou descartada. O consumo de silagem apresenta-se como o principal fator de risco para a ocorrência da doença (Morin, 2004; Brugère-Picoux, 2008; Ribeiro et al., 2006; Driehuis, 2013). Entretanto, surtos da enfermidade já foram registrados em ruminantes alimentados com pastagem nativa (Rissi et al., 2010), feno (Brugère-Picoux, 2008), cama-de-frango, subprodutos de soja e variedade de outros grãos (Morin, 2004).

Os sinais clínicos observados na única ovelha examinada incluíam apatia severa, febre $\left(40^{\circ} \mathrm{C}\right)$, cegueira bilateral com midríase, mucosas oculares hiperêmicas, narinas com secreção serosa e sujidades, hipotonia lingual e torneio para a direita com episódios de quedas esporádicas. Tais achados são semelhantes aos descritos em estudos anteriores (Guedes et al., 2007; Rissi et al., 2006; 2010; Brugére-Picoux, 2008; Mayhew, 2009), sendo os sinais neurológicos associados às lesões do tronco encefálico e consequente comprometimento dos nervos cranianos, principalmente trigêmeo, abducente e oculomotor. Neste surto, os coeficientes epidemiológicos de morbidade $(1,5 \%)$, mortalidade $(1,5 \%)$, e letalidade $(100 \%)$ foram semelhantes aos achados de Rissi et al. (2006, 2010), ao afirmarem que a morbidade e mortalidade variava de $1-10 \%$, enquanto a letalidade atingia, na maioria dos casos, $100 \%$.

A linfopenia absoluta acarretando a inversão da relação linfócito/ neutrófilo $(0,16)$ foi a única alteração hematológica e a bioquímica 
sérica apresentou-se dentro dos limites fisiológicos para a espécie (Tabela 1). Tais achados confirmam que as análises hematológicas e bioquímicas são de pouco valor diagnóstico, e que a leucocitose não é um achado consistente da enfermidade (Brugére-Picoux, 2008), enquanto a linfopenia é relatada em situações de estresse, administração de corticosteróides, imunodeficiências raras, infecções virais ou bacterianas agudas (Jones e Allison, 2007). A análise do LCR revelou aspecto turvo, presença de retículo de fibrina e pleocitose neutrofílica com 92 leucócitos/ $\mu \mathrm{L}$ (Tabela 1), dos quais $65 \%$ consistiam de células polimorfonucleares. Os resultados confirmam que a pleocitose (aumento na celularidade do LCR) neutrofílica é tipicamente associada à infecção bacteriana aguda (Stokol et al., 2010). A diferenciação das células nucleadas encontradas no LCR de ruminantes é composta quase que exclusivamente por células mononucleares, sendo evidenciada a elevação de granulócitos neutrofílicos polimorfonucleados em processos purulentos (Mayhew, 2009; Scott, 2010), como neste caso de meningoencefalite. O exame bacteriológico de amostras do LCR de três animais durante a necropsia e do ovino examinado clinicamente permitiu o isolamento e caracterização da L. monocytogenes. Assim, o cultivo de tecido do SNC ou LCR apresenta-se como ferramenta laboratorial útil para o diagnóstico definitivo de meningoencefalite em ovinos.

Os achados macroscópicos limitaramse a leve congestão das meninges e LCR turvo. Microscopicamente, a principal característica foi a meningite, caracterizada por infiltrado difuso de células mononucleares (linfócitos, plasmócitos e macrófagos) e gliose focal. A presença de microabscessos multifocais, constituídos de células polimorfonucleares, localizados na região do tronco encefálico, bulbo, ponte, mesencéfalo e medula oblonga, foi marcante. Além disso, foram observados infiltrado neutrofílico e linfocítico multifocal nos fascículos do nervo trigêmeo. Portanto, nos animais deste estudo, as lesões foram características do que é geralmente descrito em casos de listeriose encefálica em ruminantes (Guedes et al., 2007; Rissi et al., 2006; 2010; Schild, 2007; Brugére-Picoux, 2008). Salienta-se ainda que, recentemente, no Brasil, a L. monocytogenes foi isolada de microabscessos da medula espinhal de um caprino com paralisia flácida dos membros posteriores e estado mental normal, sendo o primeiro diagnóstico de mielite nesta espécie por tal micro-organismo (Câmara et al., 2012).

Em humanos, a L. monocytogenes também se apresenta como um dos principais patógenos de origem alimentar e de grande preocupação para a saúde pública (Barancelli et al., 2011; Driehuis, 2013). Alimentos particularmente ligados à contaminação pela bactéria incluem peixe cru e defumado; carne crua e cozida; queijos macios e semimacios produzidos a partir de leite não pasteurizado (Koch et al., 2010; Barancelli et al., 2011; Driehuis, 2013). Os humanos são, rotineiramente, expostos a baixos números de bactérias em vários tipos de alimentos, sem que tal fato seja considerado sério problema para a saúde (Driehuis, 2013). Entretanto, quando ocorre a ingestão de alimentos contaminados com um elevado número de bactérias pode resultar em doença, principalmente nas populações com risco aumentado para listeriose, tais como pacientes imunodeprimidos, gestantes, idosos e recém-nascidos (Koch et al., 2010; Driehuis, 2013).

Diante do exposto, a prevenção da listeriose encefálica nos ruminantes é de grande interesse para a saúde pública, já que estes animais podem atuar como portadores assintomáticos da bactéria e disseminá-la através das fezes e leite (Morin, 2004; Ribeiro et al., 2006; Brugére-Picoux, 2008). Fato este comprovado por meio da comparação dos subtipos de $L$.

Tabela 1: Achados hematológicos, bioquímicos e análise do líquido cefalorraquidiano de ovino com meningoencefalite por L. monocytogenes

\begin{tabular}{|c|c|c|}
\hline \multicolumn{3}{|c|}{ HEMOGRAMA E BIOQUÍMICA } \\
\hline PARÂMETRO & CASO CLÍNICO & VALORES DE REFERÊNCIA \\
\hline Hematócrito (\%) & 35 & $22-38^{d}$ \\
\hline 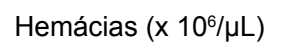 & 11,3 & $8-18^{d}$ \\
\hline Hemoglobina (g/dL) & 11,2 & $8-12^{d}$ \\
\hline $\operatorname{VCM}^{a}(\mathrm{fL})$ & 30 & $16-25^{d}$ \\
\hline $\mathrm{CHCM}^{\mathrm{b}}(\%)$ & 32 & $30-36^{d}$ \\
\hline $\mathrm{PPT}^{\mathrm{c}}(\mathrm{g} / \mathrm{dL})$ & 6,6 & $6-7,5^{d}$ \\
\hline Leucócitos Totais (/ $\mu \mathrm{L})$ & 7200 & $4000-12000^{d}$ \\
\hline Neutrófilos $(/ \mu \mathrm{L})$ & 5112 & $700-6000^{d}$ \\
\hline 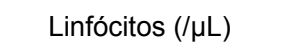 & 864 & $2000-9000^{d}$ \\
\hline Eosinófilos $(/ \mu \mathrm{L})$ & 360 & $0-1000^{d}$ \\
\hline 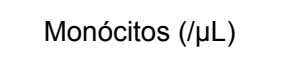 & 72 & $0-750^{d}$ \\
\hline AST (U/L) & 101 & $60-280^{e}$ \\
\hline GGT (U/L) & 32 & $20-56^{e}$ \\
\hline Creatinina (mg/dL) & 1,3 & $1,2-1,9^{e}$ \\
\hline Uréia $(\mathrm{mg} / \mathrm{dL})$ & 16 & $8-20^{e}$ \\
\hline \multicolumn{3}{|c|}{ ANÁLISE DE LÍQUIDO CEFALORRAQUIDIANO } \\
\hline PARÂMETRO & CASO CLÍNICO & VALORES DE REFERÊNCIA ${ }^{f}$ \\
\hline Aspecto & Turvo & Límpido \\
\hline Cor & Amarelo claro & Incolor \\
\hline Densidade & 1.005 & $\leq 1.010$ \\
\hline Retículo de fibrina & Presente & Ausente \\
\hline Proteína total (mg/dL) & 300 & $\leq 300$ \\
\hline Hemácias $(/ \mu \mathrm{L})$ & 176 & Raras \\
\hline Leucócitos $(/ \mu \mathrm{L})$ & 92 & $<10$ \\
\hline Cultura microbiológica & L. monocytogenes & Ausente \\
\hline
\end{tabular}

a Volume corpuscular médio; ${ }^{b}$ Concentração de hemoglobina corpuscular média; ${ }^{c}$ Proteína plasmática total; ${ }^{\mathrm{d}}$ Kramer (2000); ${ }^{\mathrm{e}}$ Kaneko et al. (1997); ${ }^{\mathrm{f}}$ Scott (2010). 
monocytogenes isolados de ruminantes clinicamente afetados aos de amostras de alimentos e casos clínicos obtidos a partir dos principais surtos de listeriose humana. Este estudo sugere que os ruminantes representam importante reservatório natural da bactéria e fonte potencial de estirpes patogênicas para os seres humanos (Rocha et al., 2013). As medidas preventivas incluem redução da exposição à bactéria em alimentos para ruminantes e no meio ambiente; prevenção de situações de estresse e doenças concomitantes que podem aumentar a susceptibilidade à infecção. No tocante à silagem, esta deve ser

\section{Referências}

BARANCELLI, G.V.; SILVA-CRUZ, J.V.; PORTO, E.; OLIVEIRA, C.A.F. Listeria monocytogenes: Ocorrência em produtos lácteos e suas implicações em saúde pública. Arquivos do Instituto Biológico, v. 78, n. 1, p. 155-168, 2011.

BRUGÉRE-PICOUX, J. Ovine listeriosis. Small Ruminant Research. v. 76, n. 1-2, p. 12-20, 2008.

CÂMARA, A.C.L.; LIMA, P.M.; BATISTA, J.S.; FEIJÓ, F.M.C.; SOTO-BLANCO, B. Pathology in practice. Journal of the American Veterinary Medical Association, v. 240, n. 3, p. 269-271, 2012.

DIFFAY, B.C.; MCKENZIE, D.; WOLF, C.; PUGH, D.G. Abordagem e exame de ovinos e caprinos. In: PUGH, D.G. Clínica de ovinos e caprinos. São Paulo, Rocca, 2004. p. 1-19.

DRIEHUIS, F. Silage and the safety and quality of dairy foods: A review. Agricultural and Food Science, v. 22, n. 1, p. 16-34, 2013.

DUNIÈRE, L.; SINDOU, J.; CHAUCHEYRAS-DURAND, F.; CHEVALLIER, I.; THÉVENOT-SERGENTET, D. Silage processing and strategies to prevent persistence of undesirable microorganisms. Animal Feed Science and Technology, v. 182, n. 1, p. 1-15, 2013.

JONES, M.L.; ALLISON, R.W. Evaluation of the ruminant complete blood cell count. Veterinary Clinics of North America: Food Animal Practice, v. 23, n. 3, p. 377-402, 2007.

GUEDES, K.M.R.; RIET-CORREA, F.; DANTAS, A.F.M.; SIMÕES, S.V.D.; NETO, E.G.M; NOBRE, V.M.T.; MEDEIROS, R.M.T. Doenças do sistema nervoso central em caprinos e ovinos no semiárido. Pesquisa Veterinária Brasileira, v. 27, n. 1, p. 29-38, 2007.

KANEKO, J.J.; HARVEY, J.W.; BRUSS, M.L. Clinical biochemistry of domestic animals. $5^{\text {th }}$ ed. San Diego, Academic Press, 1997.

$\mathrm{KOCH}$, J.; DWORAK, R.; PRAGER, R.; BECKER, B.; BROCKMANN, S.; WICKE, A.; WICHMANN-SCHAUER, H.; HOF, H.; WERBER, D.; STARK. K. Large listeriosis outbreak linked to cheese made from pasteurized milk, Germany, 2006-2007. Foodborne Pathogens and Disease, v. 7, n. 12, p. 1581-1584. 2010.

KRAMER, J.W. Normal hematology of cattle, sheep and goats, In: FELDMAN, B.F.; ZINKL, J.G; JAIN, N.C. Schalm's Veterinary Hematology. $5^{\text {th }}$ ed. Philadelphia, Lippincott Williams and Wilkins, 2000. p.1075-1084. colhida e armazenada adequadamente para alcançar e manter as condições anaeróbias, sendo recomendando o descarte de silagem com propriedades organolépticas anormais (Morin, 2004; Dunière et al., 2013).

No relato em questão, o diagnóstico definitivo de meningoencefalite por L. monocytogenes foi baseado na associação entre os dados epidemiológicos, clínico-patológicos, e, principalmente, por meio do isolamento do micro-organismo em cultivo bacteriológico. Reitera-se a importância das medidas preventivas supracitadas, a fim de reduzir a incidência da listeriose.

MacFADDIN, J.F. Biochemical tests for identification of medical bacterial. Philadelphia, Lippincott Williams and Wilkins. 2000. 901 p.

MAYHEW, I.G.J. Large animal neurology. $2^{\text {nd }}$ ed. lowa: WileyBlackwell. 2009. 453 p.

MORIN, D.E. Brainstem and cranial nerve abnormalities: Listeriosis, otitis media and pituitary abscess syndrome. Veterinary Clinics of North America: Food Animal Practice, v. 20, n. 2, p. 243-273, 2004.

NASH, M.L.; HUNGERFORD, L.L.; NASH, T.G.; ZINN, G.M. Epidemiology and economics of clinical listeriosis in a sheep flock. Preventive Veterinary Medicine, v. 24, n. 3, p. 147-156, 1995.

RIBEIRO, L.A.O.; RODRIGUES, N.C.; FALLAVENA, L.C.B.; OLIVEIRA, S.J.; BRITO, M.A. Listeriose em rebanho de ovinos leiteiros na região serrana do Rio Grande do Sul: relato de caso. Arquivo Brasileiro de Medicina Veterinária e Zootecnia, v. 58, n. 3, p. 316-319, 2006.

RISSI, D.R.; RECH, R.R.; BARROS, R.R.; KOMMERS, G.D.; LANGOHR, I.M.; PIEREZAN, F.; BARROS, C.S.L. Forma nervosa de listeriose em caprinos. Pesquisa Veterinária Brasileira, v. 26, n.1, p. 14-20, 2006.

RISSI, D.R.; KOMMERS, G.D.; MARCOLONGO-PEREIRA, C.; SCHILD, A.L.; BARROS, C.S.L. Meningoencefalite por Listeria monocytogenes em ovinos. Pesquisa Veterinária Brasileira, v. 30, n. 1, p. 51-56, 2010.

ROCHA, P.C.D.; LOMONACO, S.; BOTTERO, M.T.; DALMASSO, A.; DONDO, A.; GRATTAROLA, C.; ZUCCON, F.; IULINI, B.; KNABEL, S.J.; CAPUCCHIO, M.T.; CASALONEB, C. Ruminant rhombencephalitis-associated Listeria monocytogenes strains constitute a genetically homogeneous group related to human outbreak strains. Applied and Environmental Microbiology, v. 79, n. 9, p. 3059-3066, 2013.

SCHILD, A.L. Listeriose. In: RIET-CORREA, F.; SCHILD, A.L.; LEMOS, R.A.A.; BORGES, J.R.J. Doenças de Ruminantes e Equideos. v. 2. Santa Maria: Editora Palotti, 2007, p. 352-357.

SCOTT, P.R. Cerebrospinal fluid collection and analysis in suspected sheep neurological disease. Small Ruminant Research. v. 92, n. 1-3, p. 96-103, 2010.

STOKOL, T.; DIVERS, T.J.; ARRIGAN, J.W.; McDONOUGH, S.P. Cerebrospinal fluid findings in cattle with central nervous system disorders: a retrospective study of 102 cases (1990-2008). Veterinary Clinical Pathology, v. 38, n.1, p. 103-112, 2009. 